\title{
René Lehwess-Litzmann* \\ Is labour market policy heading for social investment in European countries?
}

\author{
An analysis of spending trends between 2006 and 2015
}

https://doi.org/10.1515/zsr-2018-0018

\begin{abstract}
From a perspective of social investment, this article analyses monetary efforts made by European countries in terms of active and passive labour market policy (LMP) between 2006 and 2015. How did spending evolve under the double impression of the social investment discourse and the crisis after 2008? How does LMP now differ from what it was before the crisis? We find that there is no real trend towards social investment in the field of LMP in recent years. This shows both in the relationship between passive and active spending and in the composition of active spending. In particular, training - crucial to a social investment approach - is further weakened in most countries' policy arrangements. Concerning levels of spending, it is shown that labour market policy gets fiscally more demanding on aggregate, while the amount of resources made available to the average individual job seeker shrinks. Spending on LMP also remains very unequal between European countries.
\end{abstract}

Keywords: Social Investment, Labour Market Policy, Spending Trends, Europe, Crisis

\section{Introduction}

Labour market policy (LMP) in European countries has long been more than just income support in the case of unemployment, i.e. passive LMP. Bonoli (2012: 188) distinguishes three phases of active labour market policies (ALMP) after World War II, each dealing in a new way with novel economic conditions. After a phase of "upskilling" job seekers and then a phase of just keeping them "busy", he observes a particular emphasis on "employment assistance" in the

*Contact: Dr. René Lehwess-Litzmann, Soziologisches Forschungsinstitut Göttingen (SOFI) an der Georg-August-Universität, Friedländer Weg 31, 37085 Göttingen, Email: rene.lehwess@sofi.unigoettingen.de 
latest phase, i.e. interventions aimed at (re-) integrating the unemployed and other non-working persons rapidly into paid employment of any kind. This phase starts in the mid-1990s with the so-called "activation turn": at European level, it was promoted by the European Employment Strategy of 1997 and the Lisbon Agenda of 2000 (van Vliet/Koster 2011: 232). However, activation is but one part of the new, overarching social investment approach (Morel et al. 2012) that became prominent in the European policy discourse since the Lisbon Agenda (Vandenbroucke/Vleminckx 2011), the other being investment in human capital. According to De Deken (2012), “[t]he return on investment that is hoped for is an increased labour market participation of the population as well as a higher productivity of those participating” (2).

The present article provides an analysis of LMP spending trends in European countries in recent years. These years were marked above all by the Great Recession and its impacts on both labour markets and state budgets. These macroeconomic conditions clash with the social investment approach that takes a preventive stance to labour market problems and requires substantial monetary resources. Still, some years into the crisis, the European Commission (2013) encouraged EU Member States to further pursue the social investment track. ${ }^{1}$ How does European countries' LMP spending evolve in this situation, marked by the need to react quickly to pressing social and labour market problems, the request to keep up social investment, and the necessity to keep public finances under control? Does LMP now differ from what it was before the crisis? Does employment assistance remain the main orientation of LMP? What about expenditure on training, the measure most closely connected to the human capital aspect of social investment? Finally, how does the relationship between active and passive interventions evolve - is there any sign of increased "resource competition"? We chose a descriptive method to answer to these questions; neither causality concerning the genesis of policy nor the effects of policy are dealt with in this article. ${ }^{2}$

1 The European Commission did so in spite of a discussion whether a shift to social investment was part of the reasons why the poverty targets of the Lisbon process were missed (Cantillon 2011; Vandenbroucke/Vleminckx 2011).

2 These questions occupy separate fields of research: The field of comparative political economy (see the recent publications of Vlandas (2013) and Cronert (2017), for example) highlights the importance of partisan politics and regime types (Esping-Andersen 1990; Hall/Soskice 2001) for the formulation of national policies. The field of evaluation research analyses labour market policy outcomes mostly in terms of (un)employment rates, using either micro-level or aggregate effects studies. See Card et al. (2015) for an overview. 
The following section discusses the relationship between social investment and different categories of LMP spending and dicusses contemporary research on LMP spending trends. Section 3 introduces the data and method of our analysis. Section 4 comparatively analyses the evolution of active and passive LMP, while section 5 is dedicated to developments within the ALMP spending block. The final section of the paper summarises our findings and provides our conclusions. ${ }^{3}$

\section{Labour market policy from a social investment perspective: the state of knowledge}

In comparing other fields of social policy, like family-, education-, or old age policy, labour market policy is unique; it makes up a relatively small fraction of total social spending (cp. Nikolai 2012), but it is crucial for a social investment strategy (De Deken 2012). The OECD and Eurostat, as providers of cross-country harmonised spending data, register LMP spending as expenditure specifically aimed at three groups: unemployed persons, persons at risk of unemployment, and inactive persons who would to be employed (Eurostat 2013: 7-8). Total LMP expenditure can be subdivided into three categories (13): service, measures and supports. Services comprise public employment services (PES), including interactions with job seekers and the administration of measures and supports. Measures include training, employment incentives, supported or sheltered employment and rehabilitation, direct job creation and start-up incentives. ${ }^{4}$ Supports include out-of-work income maintenance and early retirement benefits.

3 We are indebted to colleagues from the Re-InVEST network for fruitful discussions on the present matter, as well as to participants at two workshops, organised by the ifz Salzburg in November 2015 and February 2017. We would also like to thank colleagues from the Sociological Research Institute (SOFI) Goettingen and two anonymous reviewers for valuable advice that contributed to our article.

4 Training aims to increase the employability of job seekers by boosting their human capital. Employment incentives support employment by subsidising the labour costs faced by employers or employees. Expenses for job rotation and job sharing are also counted in this category. Sheltered and supported employment and rehabilitation "covers measures that aim to promote the labour market integration of persons with reduced working capacity" (Eurostat 2013: 18). Direct job-creation creates additional jobs, "usually of community benefit or socially useful" (19), while start-up incentives encourage job seekers to start their own business by providing cash benefits, loans, facilities, business advice, etc. (20). 
In line with established terminology, measures will be referred to as active labour market policy (ALMP) in the analysis. They are designed to bring programme participants into employment. Supports will be referred to as passive labour market policy (PLMP). They "compensate individuals for disadvantage caused by labour market circumstance" (8). This distinction ${ }^{5}$ echoes the difference between social protection and social investment: the latter approach advocates that social policy should help persons succeed in the market, rather than just compensating unwanted market outcomes: preparing instead of repairing (Morel et al. 2012: 9; Nikolai 2012: 92). Yet, the match is not as clear as it may seem: on the one hand, not all ALMP is equally social-investment friendly, and on the other, PLMP can also have a forward-looking character: it supports workers' capacity to invest in themselves and their families in times of hardship (Nicaise/Schepers 2013: 213), and compensatory payments also prevent the loss of human capital by allowing workers to wait for a job that matches their acquired qualification. De Deken (2012) points out the importance of the duration of payments; however, if social benefits allow a long-term exit from the labour force, this can incite workers to hold onto outdated skills, and it conflicts with the aim of social investment to increase employment.

As for ALMP, several scholars have pointed to the crucial difference between enabling and constraining measures, in the words of Bonoli (2012: 183) "those which are about improving human capital, and those which use essentially negative incentives to move people from social assistance into employment” (cp. also Vlandas 2013: 5). As both traits are not mutually exclusive, Bonoli proposes to consider them as dimensions by which ALMP measures can be classified. He terms the first dimension "human capital investment" and the second "pro-market employment orientation". ${ }^{6}$ Bonoli chooses to consider only those ALMPs that score on both dimensions, i.e. they boost human capital and are connected to regular jobs, as genuine examples of social investment. Such measures reduce the burden of unemployment both for the concerned person and society, without substituting unemployment for jobs of low quality and low productivity. Among the four types of ALMP that Bonoli discusses, he argues that two qualify as genuine examples of social investment: "employment assistance" (facilitating contacts between job seekers and

5 It remains a contested distinction as activation blurs the line between ALMP and PLMP. Withholding benefits by introducing availability requirements and sanctions can be used as a means to reduce unemployment (van Vliet/Koster 2011: 234).

6 Nelson (2013) adds "distributive consequences" as a third dimension, asking whether programme participants are privileged over other workers. 
potential employers) and "upskilling" (investing in human capital). "Incentive reinforcement" (mere activation) and "occupation" (keeping jobless people busy) are not, or much less, accepted as examples of social investment (Bonoli 2012: 185-186).

Each of Bonoli's types of ALMP comprises one or several concrete ALMP spending categories. Among the ones for which data is available (see above), we can attribute training to the "upskilling" type, direct job-creation and supported or sheltered employment and rehabilitation to the "occupation" type, as well as employment incentives and start-up incentives to the "employment assistance" type. Bonoli (2012: 187) also includes expenditure on PES and administration in the "employment assistance" ALMP type, but this spending category also includes the cost of administering supports, among other things, so further disaggregation is required. As for "incentive reinforcement", it is a type of ALMP that cannot be adequately expressed by spending data. ${ }^{7}$

A severe drawback of any classification of ALMP spending lies in their internal heterogeneity, caused by unobserved design features. For example, Vlandas (2013: 6) points out that in the case of spending on services, it is "entirely unclear whether this benefits the unemployed or whether PES is used to monitor benefit recipients more closely”. Similarly, Clasen et al. (2016: 30) highlight that spending on public job-creation schemes can mean substantially different things according to whether they are well-paid or not: social participation and preservation of human capital, or just a test of availability and "workfare" (Nelson 2013: 259). Even training can be reduced to a mere way of keeping unemployed persons "busy" if the content and presentation of courses is poor or if acquired competences cannot be put to use due to mass unemployment (Bonoli 2012: 199). Clasen et al. (2016: 30) view these ambiguities as the reason why "controversies over the determinants of ALMP effort have proved rather difficult to resolve". In the case of descriptive analyses like the present one, these ambiguities impact the validity of comparisons between countries over time.

\subsection{Past and present trends of LMP spending}

What do we know about recent developments in European countries' spending on labour market policy? There are far fewer analyses of spending trends than

7 E.g. the administrative cost of benefit sanctions to job seekers does not properly reflect the status and relevance of this approach in a country's ALMP arrangement. 
there are on the determinants and the consequences of LMP spending. Two studies that exploit the full historical depth of the OECD SOCX database are offered by Nikolai (2012) and Bonoli (2012), who examine the period from 1985 to 2005, respectively 2007. Similarly using OECD data, Betcherman et al. (2004) look at developments between 1990 and 2002. A more recent period (20002010) is analysed by Kuitto (2016) for European countries, drawing on Eurostat data. Similar to our own analysis in terms of data and time frame is the short overview provided by the ETUI (2018: 40-41). Among the mentioned works, Bonoli's (2012) is the only study that distinguishes between ALMP types, while the others treat ALMP as one aggregate category, which they compare either to other social-investment related fields of spending or to conventional social protection. Most of these studies analyse spending as a percentage of GDP. Taking into account the labour market situation, Kuitto (2016: 456) weights spending by the unemployment rate and the ETUI by the number of persons wanting to work.

First, abstracting from developments over time, all authors point out the "extreme levels of cross-national variation" (Nikolai 2012: 203) in ALMP expenditure. There is disagreement whether regime types matter: Nikolai (2012: 203) states that "traditional regime analysis (Esping-Andersen 1990) no longer represents a valid framework”. Against this, Bonoli (2012: 185) finds big variations across countries, with Nordic welfare states spending a great deal, Liberal and Southern spending comparatively little, while continental welfare states fall in the middle. There is also a difference by type of ALMP: while in Nordic countries, "upskilling" is favoured, Liberal welfare states emphasise "incentive reinforcement" and Continental countries - up to the early 1990s - "occupation”.

On spending trends, Nikolai (2012: 101) reports a relative stability of aggregate ALMP expenditure in OECD countries since the mid-1980s (before this time there is no available data), where mean expenditure is at $0.67 \%$ of GDP, to 2007 , where it is at $0.63 \%$ of GDP. She observes that "the activation turn in the $1990 \mathrm{~s}$ and the rise of the social investment perspective in the 2000s are not reflected in higher expenditure on active labour market policy" (102). At the same time, she finds a "very modest decrease" (103) in spending on unemployment benefits, but considers that "[c]ompared to the increasing expenditure for old age or families, the expenditure for unemployment benefits remains stable" (Nikolai 2012). Betcherman et al. (2004: 9) have put more emphasis on a decline of social protection expenditure after 1993, but confirm a stability of ALMP expenditure between 1990 and 2002 in OECD countries. They show that while PLMP spend- 
ing is almost double that of ALMP spending in 1993, it is higher by only about one third in 2003.

For her more recent observation period from 2000 to 2010, Kuitto (2016) analyses changes in social investment and welfare spending compensation for working-age persons. With regard to a possible turn toward social investment spending, she finds "highly mixed" (453) evidence across European countries. Rising social investment and declining compensatory spending is observed in "six quite different Western European welfare states (Denmark, Finland, Norway, Ireland, Portugal and Great Britain)”, but inverse cases can also be observed (in Italy and the Netherlands), as well as countries with rising or declining expenditure of both types. The ETUI (2018: 41) points out that the growth of unemployment exceeded the growth of LMP spending in most countries between 2005 and 2018, a sign of "policy resources not moving in line with needs”.

Taking a deeper look into ALMP spending, Bonoli (2012: 188) observes a decrease in public job-creation between 1985 and 2005 and a decline in training between 2000 and 2005. In contrast, there is a long-term increase in spending on forms of "employment assistance" in all countries analysed, except Sweden. The activation turn is thus visible within ALMP. The more important part of social investment, human capital formation, is not reflected in spending accounts, and, as Bonoli argues in a longer historical perspective, it is currently weaker than in the 1950s and 1960s (182). In the following section, our actualisation of Bonoli's analysis will show that this has not changed for the better in the years after 2005.

\section{Data and method}

The basis of this investigation is a database on LMP expenditure provided by Eurostat and the EU-Commission's DG Employment, Social Affairs \& Inclusion (DG EMPL). ${ }^{8}$ Our sample includes 27 countries. ${ }^{9}$ All are members of the EU except Norway; some EU countries (Croatia, United Kingdom) are not included due to a lack of data in some years. Our observation period reaches from 2006,

8 Download at:https://ec.europa.eu/eurostat/web/labour-market/labour-market-policy/maintables, last visited 2018-04-16. Alternatively, we could have drawn on the OECD SOCX database, which features particularly long time series; however, at the time of writing, less information was available for the most recent years.

9 AT BE BG CY CZ DE DK EE EL ES FI FR HU IE IT LT LU LV MT NL NO PL PT RO SE SI SK. 
the eve of the Great Recession, to 2015, the year with the most recent data available at the time of writing. We will compare the beginning of our observation period with the end. The timing of our study has the advantage that we do not compare spending between "normal" times and "extraordinary" times: we consider that no conclusions on spending trends and welfare state recalibration can really be drawn from taking the peak of the Great Recession as a reference point. Instead, we compare the situation before 2008 with a moment when the grip of the crisis on European countries began to loosen. ${ }^{10}$

\subsection{Levels and units of analysis and their meaning}

Expenditure data comes in two different units: Percentage of GDP and Purchasing Power Standard (PPS). The former is relative spending and it reflects the share of a country's wealth that is allocated to it. The latter is in absolute, or real terms. Each can be expressed either as aggregate spending or as need-adjusted spending. We calculate it by dividing aggregate spending by the number of persons wanting to work, drawing again on Eurostat figures. This includes both the unemployed and persons in the labour reserve. The unemployed are those who fulfil the ILO definition of being without work, currently available for work and actively seeking work. The labour reserve includes inactive persons who would like to work. ${ }^{11}$

The difference between relative and absolute expenditure can be important in comparing countries: for example, rich countries can mobilise considerable resources for LMP without using a large share of their wealth, even when LMP has a low policy priority. One problem with the relative spending indicator is its sensitivity to fluctuations in the business cycle: in a recession, for example, spending as percent of GDP automatically rises due to the drop in GDP. When looking at developments within countries over time, the absolute spending indicator is therefore more precise. In comparisons between countries, graphical presentations better illustrate marked differences in absolute spending than

10 This is not to ignore the persistent youth unemployment in Southern Europe and the fiscal debt accumulated by anti-crisis measures.

11 Deflating by the number of persons wanting to work instead of the unemployment rate, we avoid the problem that countries feature different extents of economic inactivity (Clasen et al. 2016: 27). We do not escape the endogeneity problem of the deflator; however, the deflator is automatically smaller when the number of persons in ALMP measures rises (Clasen et al. 2016: 27). 
relative spending. The same holds for aggregations across countries, where large spenders otherwise eclipse small spenders.

As for aggregate and need-adjusted expenditure, the relevance of the indicator depends on whether one takes a macro- or a micro perspective. Fiscally, aggregate spending is more relevant, but from the perspective of the individual person, it is spending per head which counts. Aggregate spending depends on current labour market strain, but we will see that also per-head expenditure is not absolutely independent from the total number of persons wanting to work.

\subsection{Deflation of absolute spending: adjusting for price differences between countries and over time}

Absolute spending amounts require some modification in order to become comparable between countries and over time. First, to offset the effect of inflation, nominal spending in each country's national currency (NAC) is deflated by each year's consumer prices, using the Harmonised Index of Consumer Prices (HICP). ${ }^{12}$ Here, the price level of the year 2011 is taken as the basis $(2011=1)$. Second, the resulting time series of real national spending on LMP are further divided by the country's Purchasing Power Parity (PPP) of the same year 2011..$^{13}$ This leads to a panel of spending data in the artificial currency unit of Purchasing Power Standard (PPS) in terms of the year 2011. We can thus think of one PPS as the equivalent of what a Euro could buy on average in the observed countries in the year 2011.

\subsection{Limitations of research with expenditure data}

Doing research with expenditure data has one big advantage and many small disadvantages. The advantage is its inherent matter-of-factness (De Deken 2013). As for the disadvantages, one is the issue of unobserved design features, addressed above: it concerns research in general, but research on ALMP spending in particular. A further issue, common to comparative research, lies in the imperfect harmonisation of data, in the sense that not all countries necessarily

12 According to Eurostat (Eurostat 2008: 12), the HICP is "the official measure of consumer price inflation in the euro area".

13 PPPs "are indicators of price level differences across countries. They indicate how many currency units a particular quantity of goods and services costs in different countries" (Eurostat 2008: 49). 
report expenditure in a consistent manner. Some kinds of spending may be reported as LMP only by some countries, in particular as reporting is as a deliberate act with a signalling value for stakeholders inside and outside of the country (e.g. voters, multinational companies). In this analysis, we are unable to control for this kind of inaccuracy. In a criticism of the frequently used OECD SOCX database - but one which holds for Eurostat data, as well - Clasen et al. (2016: 25) enumerate further issues that concern ALMP spending data, including an underreporting of sub-national expenditure (municipalities and local governments) which "inevitably leads to a serious distortion of any kind of comparative analysis". The privatisation of service provision compromises the quality of national administrative data; in particular, black box contracts make an exact accounting for the category of ALMP intervention impossible (26). Non-targeted, generalised expenditure is omitted, countries that spend on everybody, not just on persons at the labour market, are therefore underreported (28). In a similar vein, in some countries part of the benefits received by the unemployed are not labelled as unemployment benefits, but instead as, for example, housing allowances (De Deken 2013). Harmonisation problems between countries are partly disposed of when comparing spending within countries over time, which will be our main focus. Still, all the mentioned drawbacks make our analysis, like any LMP spending analysis so far, an imperfect approximation of real spending trends.

\section{Active and passive expenditure - does one crowd out the other?}

We begin our analysis with a comparison of spending on active and passive labour market policies; types of ALMP will be distinguished only in section 5 . The main question we will analyse here is whether active expenditure crowds out passive expenditure under the impression of the social investment discourse, or whether passive expenditure gets even more important as a means to repair the social damage done by the crisis.

Looking at average spending amounts across our country sample, there are three observations to make. First, expenditure on passive LMP dominates active expenditure in all observed years, while labour market services are the smallest spending category (ETUI 2018: 40). This is shown in Figure 1, which depicts relative spending, thus the mean share of countries' wealth dedicated to LMP. On the left is aggregate expenditure, on the right need-adjusted expenditure, i.e. 
deflated by the share of the population wanting to work. Aggregate PLMP spending is almost exactly double ALMP spending both in 2006 and 2015, at the mean across our sample countries. We see a small increase of ALMP relative to PLMP per person wanting to work (from 49.3\% in 2006 to 53.7\% in 2015). A sustained shift in the relationship between average active and passive spending is not visible in either direction in the observation period. We take this as a sign that there is no sharpened "resource competition" (Vandenbroucke/Vleminckx 2011) between active and passive spending.
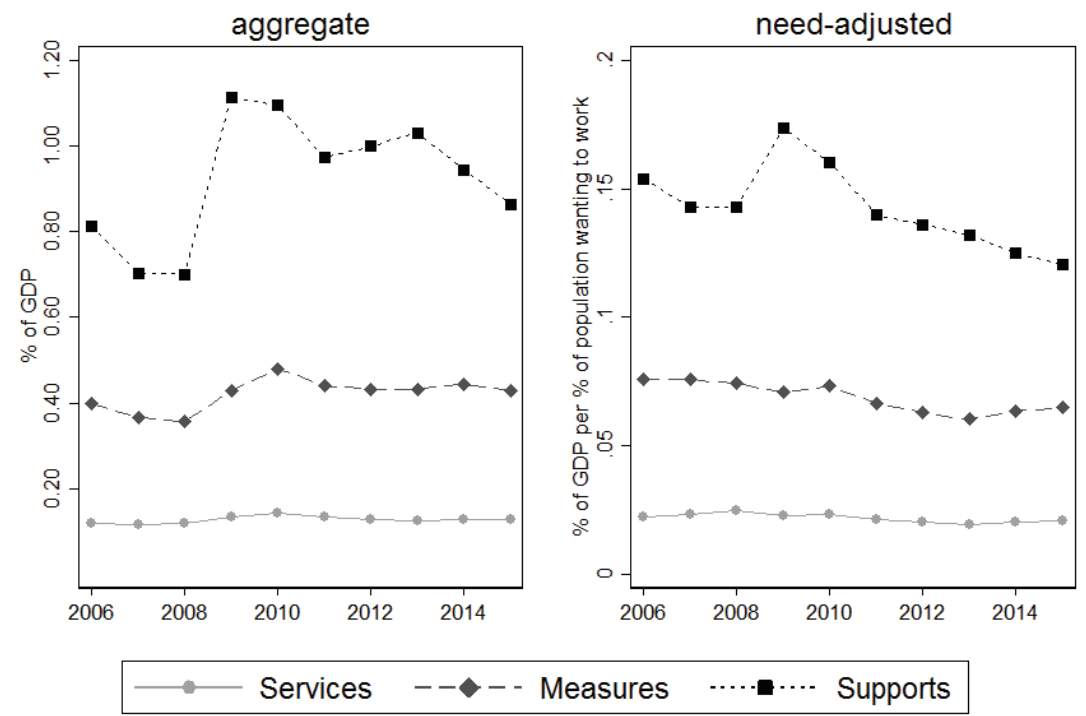

Figure 1: Relative LMP spending, European* mean, 2006-2015

Source: Eurostat/DG EMPL, own calculations. *includes AT BE BG CY CZ DE DK EE EL ES FI FR HU IE IT LT LU LV MT NL NO PL PT RO SE SI SK

However, our second observation is that the predominant short-term reaction to the crisis was in terms of supports rather than measures: for the years 2009 and 2010, we see a much stronger bulge in PLMP spending as compared to ALMP. The largest overhang is observed in 2009, where passive spending amounts to approximately 2.5 times the active spending volume. A plausible explanation lies in the distinction between "mandatory" and "discretionary" spending (Streeck/Mertens 2011): job seekers are legally entitled to a certain level of supports for a certain period of time, while training programmes, employment subsidies etc. are not automatically offered by the PES. 
Our third observation is that aggregate expenditure rises a bit in the course of the observation period, while spending per person wanting to work declines. On the aggregate level, PLMP and to some extent also ALMP expenditure are greater at the end of the observation period than at its beginning, whereas needweighted expenditure (right side of the graph) is smaller. ${ }^{14}$ This means that LMP becomes heavier fiscally, while the value of measures and supports that reaches the individual job seeker shrinks. Depending on the country, the latter phenomenon can be explained by policy reform ("retrenchment"), but also by a lack of reform (“policy drift”, cp. ETUI 2018: 41; Streeck/Thelen 2005: 24-26), e.g. in a situation where statutory entitlements run out due to sustained labour market strain.

The averages just reported are unweighted, small countries thus weigh more than the size of their population or their GDP would suggest. In the following, we will look at spending trends at the country level. ${ }^{15}$

\subsection{Spending trends at the country level}

There is a bulge of LMP spending in most countries during the crisis years from 2009 on, but the steep increases are soon reversed and spending returns to its pre-crisis level or trajectory in many countries. To determine the longer-term direction of LMP spending, we abstract from the special situation in the midst of our observation period and compare amounts spent in the years 2006 and 2007, the eve of the crisis, with amounts in 2014 and $2015 .{ }^{16}$

Table 1 reports trends of absolute expenditure by country, distinguishing between ALMP and PLMP. Aggregate expenditure is shown in the left half of the table, need-adjusted expenditure in the right half. For aggregate expenditure, a rising trend is evident: 19 out of 27 observed countries spend at least $5 \%$ more on ALMP at the end of the reference period, and 16 out of 27 raise their PLMP expenditure by at least 5\%. In 10 countries, both ALMP and PLMP expenditure increase. At the opposite side, there are only two countries with decreased

14 Persons who access a measure are not counted any more in the number of persons wanting to work. If aggregate spending on ALMP rises, fewer persons are thus in the denominator of our need-adjusted indicator. Spending per person wanting to work is thus over- rather than underestimated here.

15 Due to space constraints, we cannot provide yearly spending information on each country in this article. Please refer to our online tables: https://doi.org/10.1515/zsr-2018-0018

16 Using the mean over two years smooths over short-term fluctuation. 
ALMP and PLMP expenditure on aggregate, Germany and Romania. No country shows overall stability of aggregate expenditure.

Table 1: Trends in absolute LMP spending (PPS) on aggregate, from 2006/2007 to 2014/2015

\begin{tabular}{|c|c|c|c|c|c|c|}
\hline \multirow[b]{2}{*}{ PLMP } & \multirow{2}{*}{\multicolumn{2}{|c|}{$\begin{array}{l}\text { on aggregate } \\
\text { ALMP }\end{array}$}} & \multirow[b]{2}{*}{ falling } & \multicolumn{3}{|c|}{$\begin{array}{l}\text { per person wanting to work } \\
\text { ALMP }\end{array}$} \\
\hline & & & & $\begin{array}{l}\text { ALMP } \\
\text { rising }\end{array}$ & stable & falling \\
\hline rising & $\begin{array}{l}\text { AT CY EE FI } \\
\text { FR, IE LT LU } \\
\text { SI SK }\end{array}$ & NO & $\begin{array}{l}B G \mathrm{ES} / T \mathrm{LV} \\
\mathrm{NL}\end{array}$ & CZ EE, LV SI & LT & $\begin{array}{l}\text { BG DE IE IT } \\
\text { NO }\end{array}$ \\
\hline stable & CZ EL MT PT & - & - & AT SK & $\mathrm{Fl}$ & - \\
\hline falling & $\begin{array}{l}\text { BE DK HUPL } \\
S E\end{array}$ & - & DE RO & HU MT PL SE & - & $\begin{array}{l}\text { BE CY DK EL } \\
\text { ES FR LU NL } \\
\text { PT RO }\end{array}$ \\
\hline
\end{tabular}

Source: Eurostat/DG EMPL, own calculation. Stability defined as no more than $5 \%$ difference between initial and final amount.

From the need-adjusted perspective (right side of Table 1), the picture is more balanced, but the tendency points downward: there are 10 countries with rising and 14 with falling PLMP expenditure per person wanting to work, and there are 10 countries with rising and 15 with falling expenditure on ALMP. The largest group, 10 countries, show both falling ALMP and falling PLMP expenditure. Finland has stable expenditure within our definition of stability as less than $5 \%$ deviation from the initial value.

Cyprus, France and Luxembourg are highlighted in bold letters in Table 1, they feature a combination of rising aggregate and declining need-adjusted expenditure for both active and passive ALMP. Our third observation above applies to these three countries in particular.

Table 1 also illustrates the alignment or dissociation of ALMP and PLMP in the individual countries: in many cases, ALMP and PLMP either rise jointly or fall jointly, or both remain stable (12 in the aggregate, 15 in the need-adjusted view). In contrast, there are (10, respectively 9) countries where ALMP and PLMP per person wanting to work take opposite directions. Yet, due to the approximately equal number of countries on either side, our observation period does not seem a time of rising active interventions at the expense of passive 
interventions in Europe, or vice versa. This confirms Kuitto's (2016: 453) "mixed" findings (see above).

Table 1 highlights in italics the countries where the mix of active and passive LMP does change, both in aggregate and in need-adjusted terms: Hungary, Poland and Sweden feature rising ALMP while PLMP spending declines, while in Bulgaria and in Italy, more is spent on PLMP while ALMP expenditure shrinks.

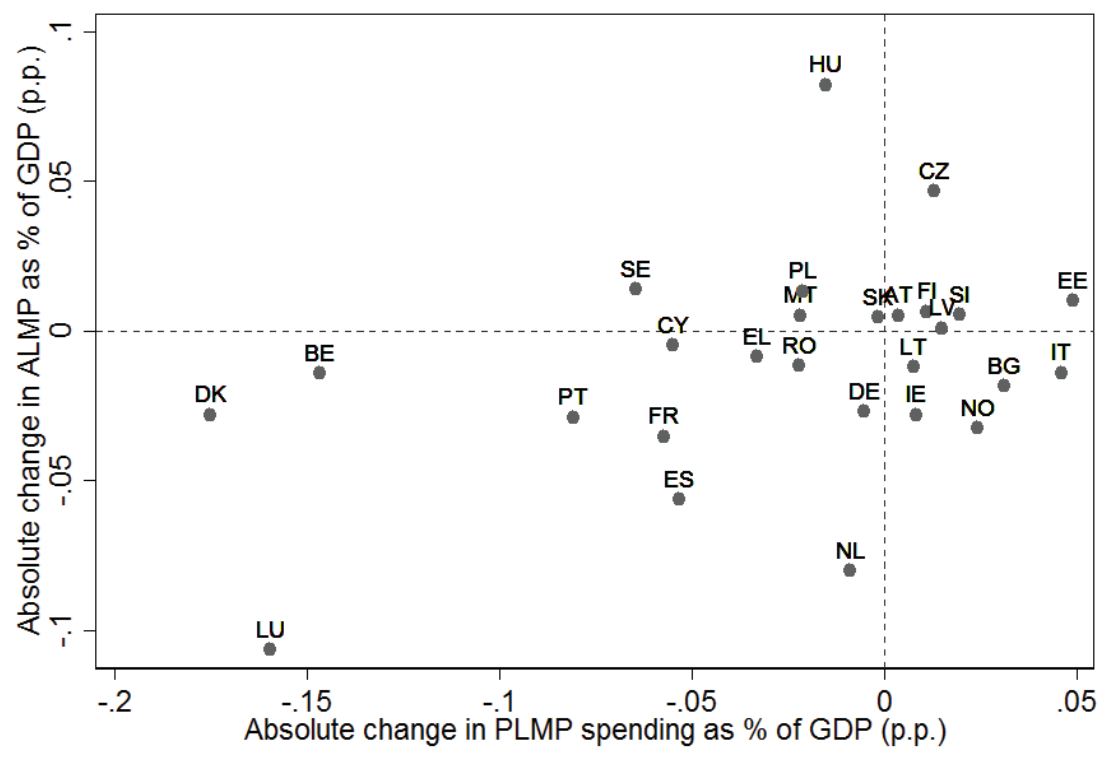

Figure 2: Absolute changes in relative need-adjusted ALMP and PLMP expenditure from $2006 / 2007$ to $2014 / 2015$, by country

Source: Eurostat/DG EMPL, own calculations

An important aspect not covered by Table 1 is the magnitude of changes. We therefore complement it by Figure 2 and Figure 3, which plot absolute, respectively relative changes of relative expenditure, ${ }^{17}$ with PLMP on the horizontal and ALMP on the vertical axis. While most countries cluster around the origin, we see strong decreases in real spending in Denmark, Belgium and Luxembourg (Figure 2). In the former two countries, decreases in ALMP are not nearly as

17 A similar picture could be shown for absolute changes of absolute spending, but its scale would be compressed by the big reductions of absolute spending in Luxembourg. 
important as decreases in PLMP: these countries (with large relative spending levels and large absolute changes, even if they are small countries) have a sizeable influence on average absolute changes of spending in Europe (Figure 1).

In Figure 3, the graph with relative changes ${ }^{18}$ four countries stand out: Hungary and the Czech Republic strongly increase their active expenditure, compared to their initial spending, while PLMP remains rather stable. Estonia boosts both active and passive expenditure. Bulgaria considerably increases its PLMP spending, relatively, while decreasing ALMP. These countries pull average relative changes of spending upwards in Europe. Relative changes are very sensitive to the starting level, which is quite low in the for aforementioned Central and Eastern European countries. The heterogeneity of countries in our sample requires European averages to be interpreted very prudently.

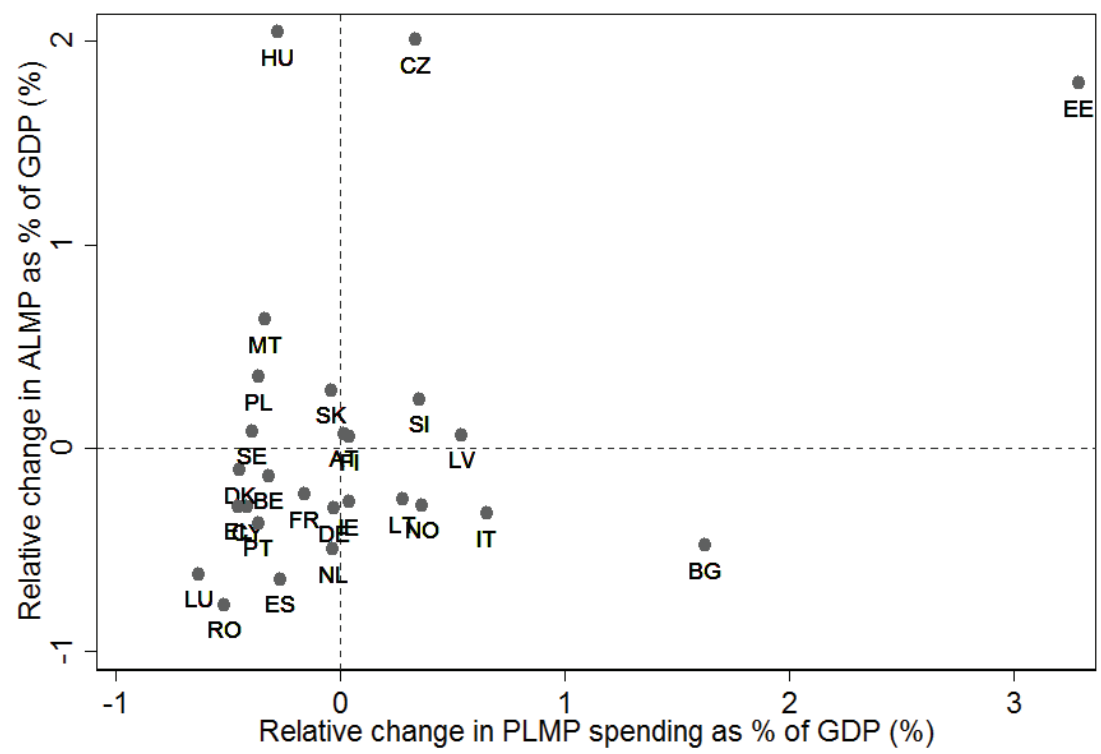

Figure 3: Relative changes in relative ALMP and PLMP expenditure from 2006/2007 to $2014 / 2015$, by country

Source: Eurostat/DG EMPL, own calculations

18 We calculate relative changes by dividing the spending amount at the end of the observation period by the value at its beginning, subtracting 1 . The relative change thus signifies how many times more is spent at the end of the observation period. 
It has become clear that our observation period is marked by quite heterogeneous LMP spending trends in our 27 sample countries. Let us examine, for illustrative reasons, two country cases with contrasting developments concerning the active/passive LMP mix: Italy and Hungary. Italy (Figure 4) is a prominent example of weak and further declining social investment. Kazepov and Ranci (2017: 98) describe Italy as an "adverse case” of social investment, "a country unfriendly to SI". In our observation period, passive expenditure increased tremendously in Italy with is a particular jump in the year 2009, and sustained for some years afterward, while active expenditure experiences a steady decline. In the last year observed, however, both trends are reversed.

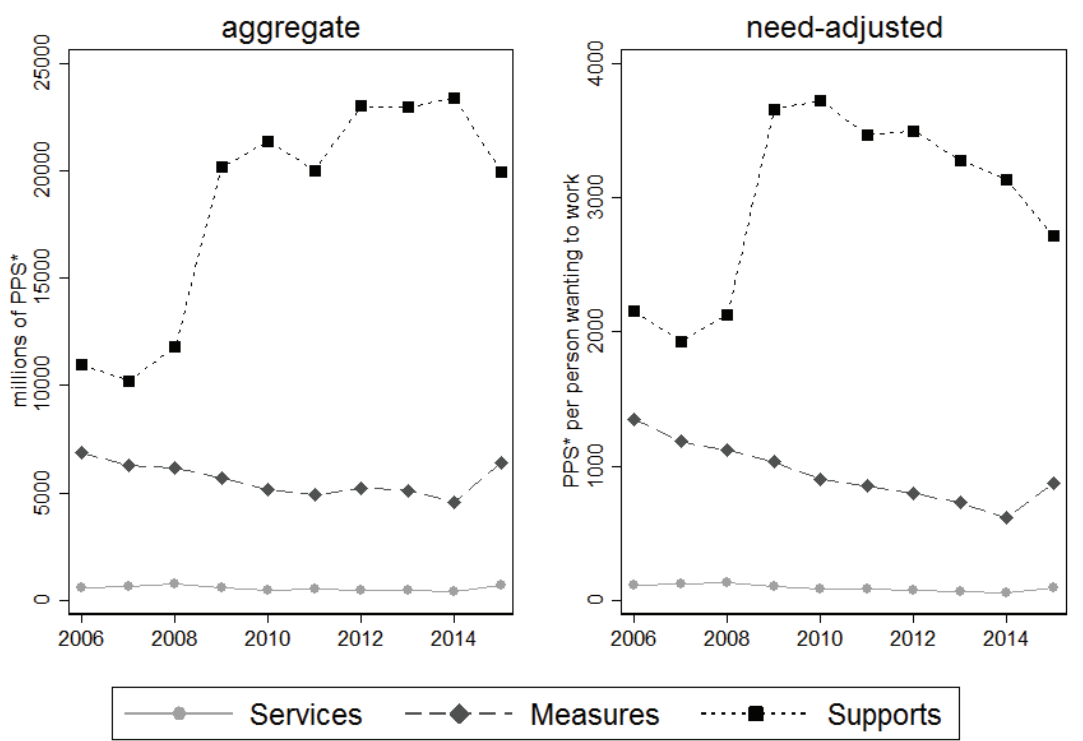

Figure 4:LMP expenditure trends in Italy, 2006-2015

Source: Eurostat/DG EMPL, own calc. *Amounts calculated at 2011 prices, divided by 2011 PPP.

In contrast, Hungary (Figure 5) is a rather spectacular case of rising ALMP, its policy arrangement changes from a dominance of passive to a dominance of active expenditure. As we will see below (section 5), this is due to a boost in public job-creation. Simultaneously, reforms to lower unemployment benefits are also reported (Bouget et al. 2015: 38). 


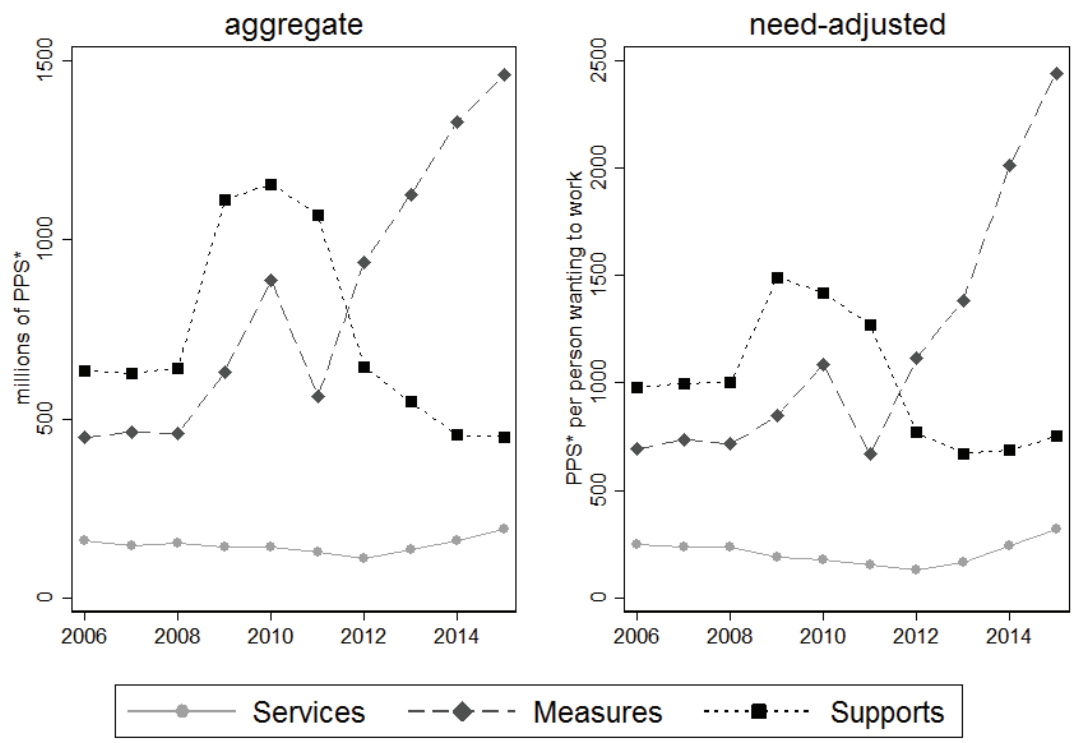

Figure 5: LMP expenditure trends in Hungary, 2006-2015

Source: Eurostat/DG EMPL, own calc. *Amounts calculated at 2011 prices, divided by 2011 PPP.

Beyond diverging trends, the two preceding graphs also show that levels of ALMP and PLMP spending can diverge between countries. In the following section, we will again examine all our sample countries: are there other cases beside Hungary where more is spent on active than on passive LMP? Can we distinguish between ALMP- and PLMP-countries in Europe?

\subsection{Are there "ALMP-" and "PLMP-countries" in Europe?}

Figure 6 and Figure 7 compare spending structures synoptically for our sample at the beginning and at the end of our observation period. The solid diagonal line marks all points where ALMP and PLMP spending are equal in size. All dots above it stand for higher ALMP, while all dots below the line stand for higher PLMP expenditure. There are two dashed lines above and two below the diago- 
nal. The two upper dashed lines mark an ALMP expenditure 50\% respectively $100 \%$ higher than PLMP spending, and vice versa. ${ }^{19}$

Clearly, a majority of countries are below the diagonal line, both at the beginning and at the end of the observation period. In 2006/2007 (Figure 6), most countries are situated in the area where PLMP is between $50 \%$ and $100 \%$ higher than ALMP, thus between the two lower-most dashed lines. Three countries go beyond this and reach into the area where PLMP is more than double ALMP expenditure: Belgium, Cyprus, Malta, and also Portugal. Some years after the Great Recession, in 2014/2015 (Figure 7), there are numerous countries with a PLMP expenditure more than twice as high as ALMP expenditure: Italy, Spain, Germany, and the Netherlands have joined, and also Estonia and France.

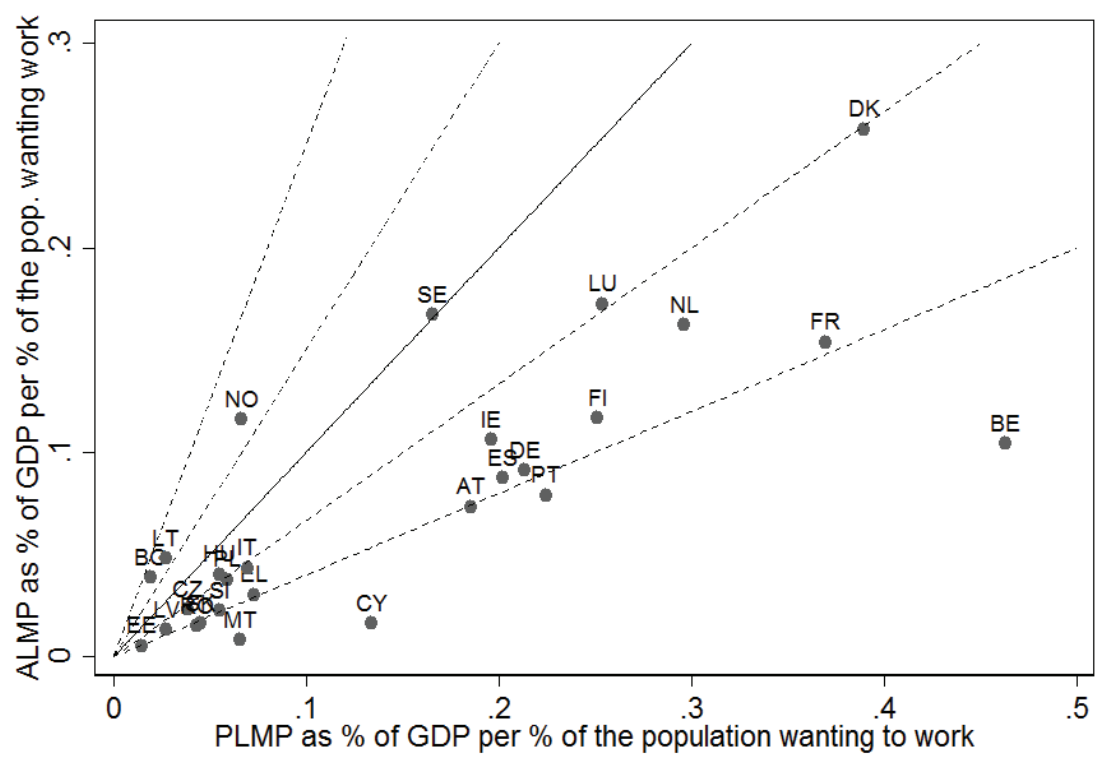

Figure 6: Active and passive relative need-adjusted LMP expenditure, mean of 2006-2007

Source: Eurostat/DG EMPL, own calculations

Norway, the only country with at least medium-sized spending leaning toward ALMP in 2006/2007, balances its expenditure between ALMP and PLMP in 2014/2015. Lithuania and Bulgaria, also leaning toward ALMP in 2006/2007

19 The two lower dashed lines thus mark a PLMP expenditure 50\% respectively 100\% higher than ALMP spending. 
(though at a much lower spending level), have split by 2014/2015: Lithuania stays ALMP-leaning, while Bulgaria switches to the PLMP side. Denmark also has balanced spending at the end of the observation period, having increased their active share of LMP. Sweden and Hungary stand out for having distinguished themselves with high levels of ALMP spending, as they are far above the diagonal in 2014/2015. This also holds for Poland and the Czech Republic; however, their spending volume is much smaller. In sum, we observe a certain fanning out during the observation period, as distinctive ALMP and PLMP profiles emerge.

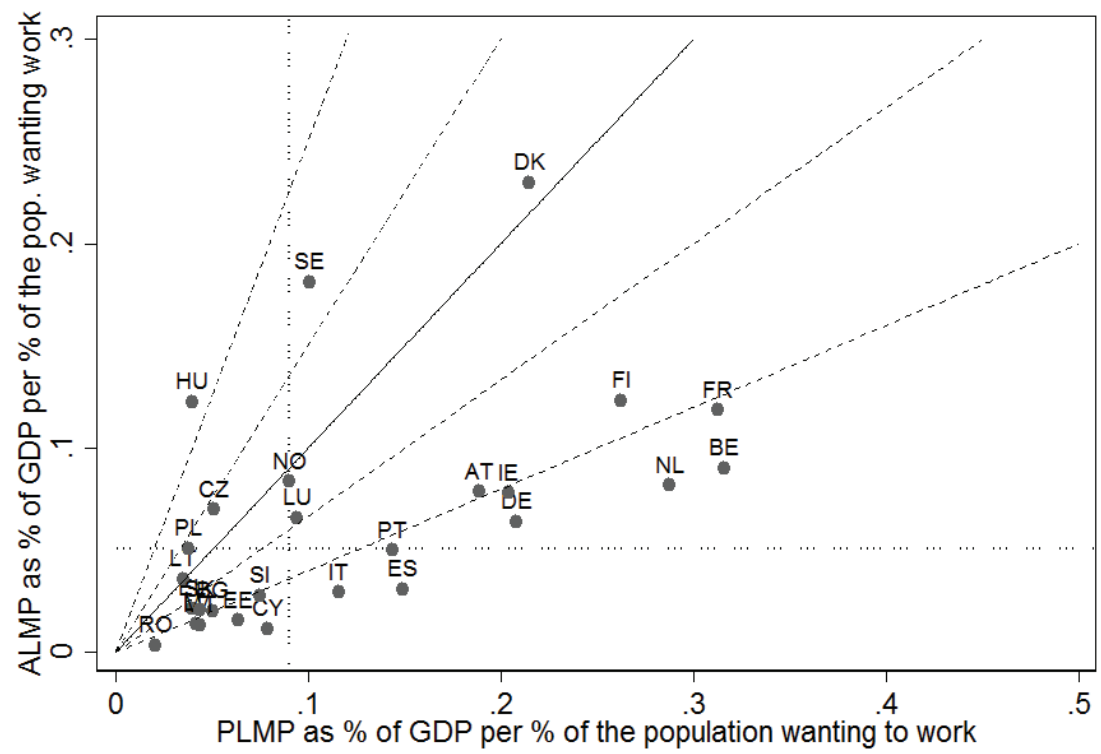

Figure 7: Active and passive relative need-adjusted LMP expenditure, mean of 2014-2015

Source: Eurostat/DG EMPL, own calculations

Another observation to make from the above two graphs is that the big spenders on PLMP reduce their spending significantly. Yet, the distinction between strong and weak LMP remains important, maybe more important than the distinction between ALMP- and PLMP-countries: we can see this in Figure 7 if we 
focus on the dotted lines; they mark median spending levels and divide the area into four quadrants. ${ }^{20}$

In 2014/2015, there are countries clearly below (above) the median in ALMP spending, but above (below) in PLMP: Hungary and the Czech Republic on the active side and Italy and Spain on the passive side. This makes that the two countries in the ALMP quadrant are Eastern and the two in the PLMP quadrant are Southern European. Yet, the 2nd (high ALMP and high PLMP) and 4th (low ALMP and low PLMP) quadrants are by far the most crowded. Our observations thus confirm for the field of labour market policy the findings of Kuitto (2016: 454) that "rather than a trade-off, there is (still) a distinction between those countries spending less on welfare policies in general (most of the CEE countries) and those spending more in both compensating and social investment policies and offering more generous benefits" (in addition, cf. Bruno/Rovelli 2010: 670). In line with Bonoli's findings (see above), welfare regimes are partly reflected here, with the biggest spenders being Nordic and Continental countries, and the smaller spenders being Southern and Eastern European. There are, however, considerable differences within these groups.

Summing up this section, there is no shift towards either active or passive expenditure in Europe as a whole between 2006 and 2015, though policy arrangements change in some individual countries and spending profiles get a bit more polarised between active and passive spending. Some Eastern European countries strongly increase their spending on ALMP (and partly PLMP) during the observation period, while some Western European countries strongly decrease their PLMP (and partly ALMP) spending. Spending on labour market policy remains drastically unequal across Europe. Moreover, we observe a reduction of spending per person wanting to work in most countries even though aggregate LMP spending increases, which has to do with rising labour market challenges.

\section{What do governments choose from the ALMP toolbox?}

This section examines active labour market policies in a disaggregate way, based on the established spending categories. Our main interest lies in the ques-

20 Instead of looking for a parity of ALMP and PLMP expenditure, they instead use separate reference points for identifying high/low active and high/low passive spending. 
tion whether the trend towards "employment assistance", identified by Bonoli (2012), continues after the beginning of the crisis in 2008. Alternatively, countries could take recourse to direct job-creation, like they did as of the mid-1970s under the impression of the oil shocks and mass unemployment (188). Equally possible would be a scenario of investment in training, as private-sector jobs became scarcer during the Great Recession and training remains a way to relieve the labour market.

We start again by looking at (unweighted) average spending across our European sample countries. Looking first at aggregate (relative) spending (left part of Figure 8), there is a clear hierarchy: training is most important, employment incentives and the category sheltered and supported employment and rehabilitation share rank number two. Much less is spent on direct job-creation and again much less on start-up incentives. In the per-head view (right part), the advance of training over employment incentives and sheltered and supported employment and rehabilitation is smaller than in the aggregate view, else the relationships between spending categories are similar.
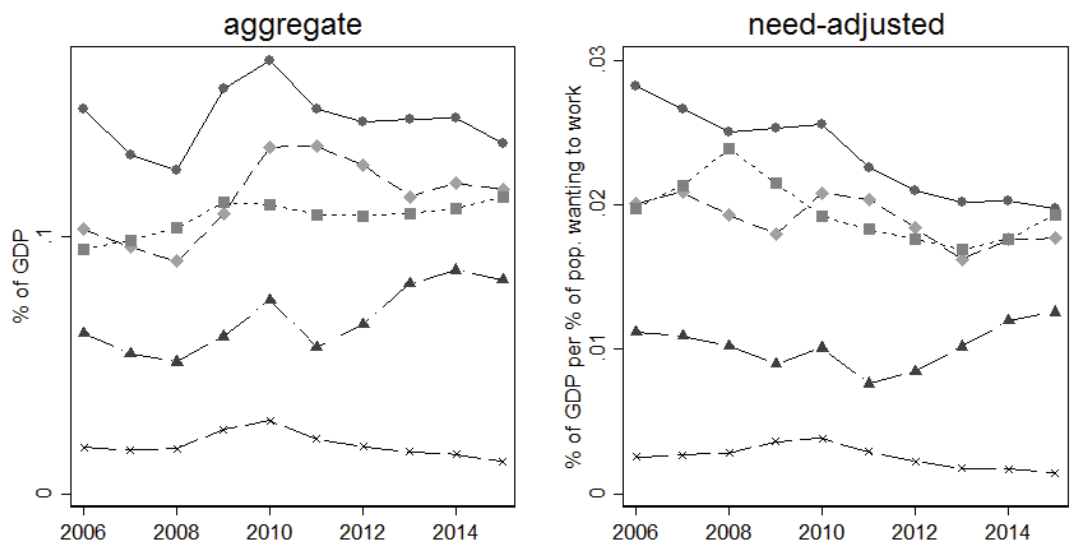

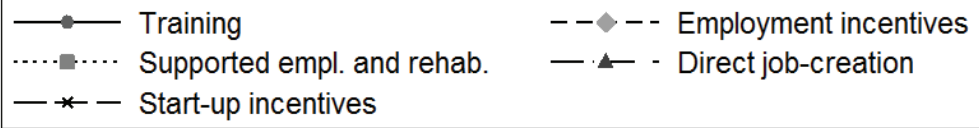

Figure 8: Relative ALMP spending, European* mean, 2006-2015

Source: Eurostat/DG EMPL, own calculations. *includes: AT BE BG CY CZ DE DK EE EL ES FI FR HU IE IT LT LU LV MT NL NO PL PT RO SE SI SK 
Let us concentrate for a moment on the change of expenditure as percent of GDP between the first two and the last two years observed: on aggregate, there is rising expenditure for the categories of employment incentives, sheltered and supported employment and rehabilitation, and direct job-creation. There is approximately stable aggregate spending on training and start-up incentives. Deflated by the number of persons wanting to work, the evolution of expenditure appears in a more negative light. ${ }^{21}$ Training in particular declines during the course of the observed period, but also employment incentives and sheltered and supported employment and rehabilitation, in spite of the rise in aggregate spending. Only for direct job-creation - where aggregate expenditure rises most - do we also see a rise in need-adjusted spending, and it mostly occurs after the year 2011.

These trends average out over heterogeneous developments in the individual sample countries, and in some cases they are driven by particularly strong changes in just a few or even just one country. ${ }^{22}$ Above all, this holds for direct job-creation, where the observed rise is almost exclusively due to Hungary. Figure 9 depicts the Hungarian ALMP spending profile: beside the skyrocketing direct job-creation, other ALMP categories continue to play a minor role. This policy shift (connected with declining PLMP, see above) has sparked a lot of critical ("workfare") and few prudently optimist comments (see Lakner/Tausz 2016; Asztalos Morell 2014; Szikra 2014; Keller et al. 2016). Beside Hungary, direct job-creation is the most significant measure also in Slovenia and Bulgaria, though in Bulgaria it has declined recently.

21 Against intuition, the relationship between trends of aggregate and per capita expenditure need not be identical across spending categories. The reason is that we are looking at the European mean over national differences in spending, not at the difference of mean spending across Europe between both points in time. This makes that the denominator for calculating the per-head value is not identical for each spending category. If a country spends a great deal on a specific ALMP category, the development of the number of persons wanting to work in this country will have a particular impact on the European mean difference per head.

22 See our above-mentioned online tables. 

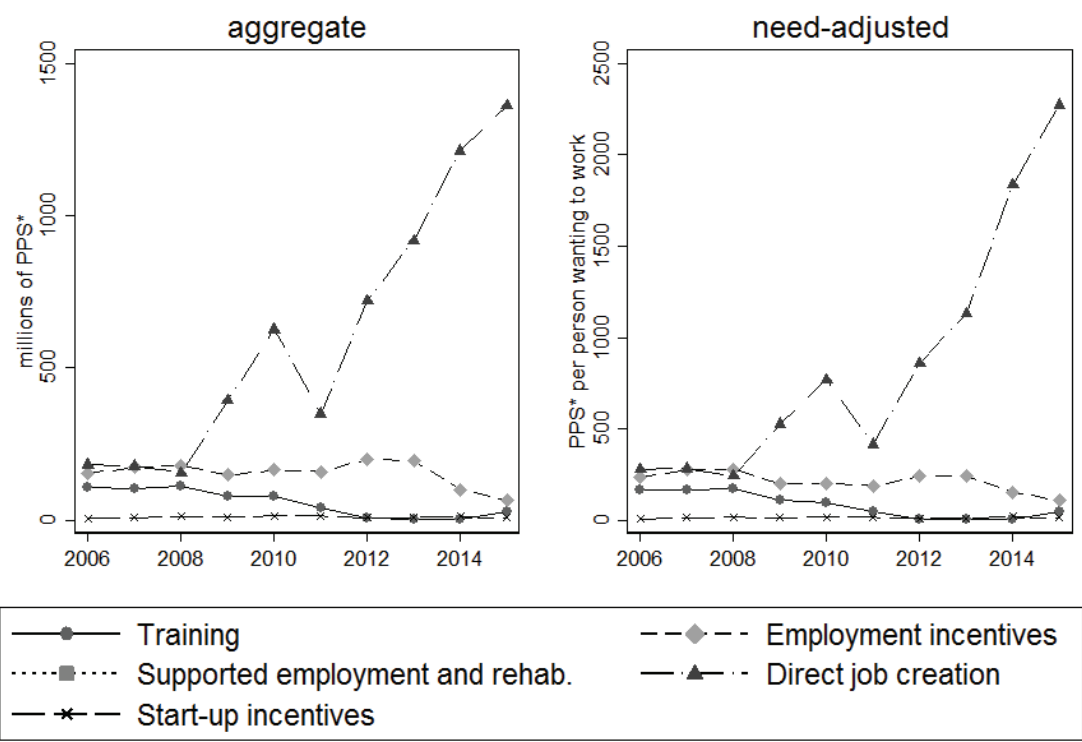

Figure 9: Spending on ALMP in Hungary, by measure

Source: Eurostat/DG EMPL, own calc. *Amounts calculated at 2011 prices, divided by 2011 PPP.

Other cases where changes in a small number of countries influence the European average are the particularly strong declines of training expenditure in Norway and Germany (aggregate), respectively Luxembourg, Norway and Denmark (need-adjusted). Aggregate spending on employment incentives, rising on average, benefits from strong gains in Luxembourg and Denmark, while Spanish expenditure withers. From a need-adjusted perspective, there are strong declines not only in Spain, but also in Luxembourg and the Netherlands, but they are partly compensated by notable increases in at least seven countries. The spending category sheltered and supported employment and rehabilitation benefits from a favourable trend in Sweden, both on aggregate and per person wanting to work. Another important country here is Denmark, with rising aggregate but declining need-adjusted expenditure. The Netherlands also show a strong decline of need-adjusted spending in this category. As for start-up incentives, the average of European countries is moved most strongly by the marked decline of spending in Germany. 


\subsection{How do ALMP arrangements change in individual countries?}

In this section, we try to get a better overview of which measures become more prominent in individual European countries, without considering outliers. Table 2 reports for each country which measure develops the most (or least) favourably between the beginning and the end of our observation period, either in relative terms, compared to initial spending on that measure, or in absolute terms, i.e. the difference in currency units. ${ }^{23}$ Developing "most favourably" does not necessarily mean an increase in spending on that measure: it may be that expenditure only shrinks less than for the other measures. In any case, the measure with the most favourable development becomes more important in the ALMP arrangement of that country. ${ }^{24}$

Table 2 reveals that the category of employment incentives experiences the strongest boost in our observation period, while training and start-up incentives are clearly losing out. Out of 27 sample countries, employment incentives are the spending category that develops most favourably in relative terms in 12 of the countries, and in absolute terms in 10 of the countries. Spending on training evolves better than all other measures only in 2 resp. 5 countries, and start-up incentives in 3 resp. 6 countries. In contrast, training experiences the least favourable development in 7 resp. 9 countries, start-up incentives in 11 resp. 5 countries. Interestingly, employment incentives are also among the measures that evolve the least favourably among all measures in quite a number of countries: in 4 countries from the relative and in 9 countries from the absolute perspective on change. Employment incentives are thus, in total, the ALMP category with the highest number of significant changes in our sample. As for the remaining two categories, spending changes appear less important, although also they change most strongly in a small number of countries.

23 It does not matter for that purpose whether we look at aggregate or need-adjusted spending, the ordering of measures does not change by deflation.

24 Vice versa for least favourable developments in the second part of Table 2. 
Table 2: ALMP measure for which spending developed most favourably between 2006/2007 and $2014 / 2015$, by country

\begin{tabular}{|c|c|c|c|c|c|}
\hline & Training & $\begin{array}{l}\text { Employment } \\
\text { incentives }\end{array}$ & $\begin{array}{l}\text { Supported } \\
\text { employment } \\
\text { and rehab. }\end{array}$ & $\begin{array}{l}\text { Direct job- } \\
\text { creation }\end{array}$ & $\begin{array}{l}\text { Start-up in- } \\
\text { centives }\end{array}$ \\
\hline \multicolumn{6}{|c|}{ Most favourable development within country } \\
\hline Relative change & 2: AT CY & $\begin{array}{l}\text { 12: CZ DK EE IE } \\
\text { IT LU MT NO PL } \\
\text { RO SI SK }\end{array}$ & $\begin{array}{l}\text { 5: BE DE ES NL } \\
\text { SE }\end{array}$ & $\begin{array}{l}\text { 5: EL FI HU } \\
\text { LV PT }\end{array}$ & 3: BG FR LT \\
\hline Absolute change & $\begin{array}{l}\text { 5: AT CY EE FI } \\
\text { NL }\end{array}$ & $\begin{array}{l}\text { 10: CZ DK IE LT } \\
\text { MT NO PL SE SI } \\
\text { SK }\end{array}$ & 2: DE ES & $\begin{array}{l}\text { 4: EL HU IT } \\
\text { LV }\end{array}$ & $\begin{array}{l}\text { 6: BE BG FR LU } \\
\text { PT RO }\end{array}$ \\
\hline \multicolumn{6}{|c|}{ Least favourable development within country } \\
\hline Relative change & $\begin{array}{l}\text { 7: DK EE HU } \\
\text { LU MT PL SI }\end{array}$ & 4: BG ES FR NL & 4: AT CY LT PT & 1: IE & $\begin{array}{l}\text { 11: BE CZ DE } \\
\text { EL FI IT LU NO } \\
\text { RO SE SK }\end{array}$ \\
\hline Absolute change & $\begin{array}{l}\text { 9: DK HU IT } \\
\text { LT MT NO PL } \\
\text { PT SI }\end{array}$ & $\begin{array}{l}\text { 9: AT BE CY EL } \\
\text { ES FI FR LU LV }\end{array}$ & $1: \mathrm{NL}$ & 3: BG IE RO & $\begin{array}{l}\text { 5: CZ DE EE SE } \\
\text { SK }\end{array}$ \\
\hline
\end{tabular}

Source: Eurostat/DG EMPL, own calculations

Bonoli (2012) found that "employment assistance" dominated the period between the mid-1990s and 2005. Against this backdrop, our results yield an ongoing trend toward employment incentives in a substantial number of countries between 2006 and 2015. Yet, we also find a downgrading of this measure in some countries, and like other measures, employment incentives do not escape the decline of need-adjusted spending (per head) on average in Europe. Start-up incentives - also part of "employment assistance" according to Bonoli (2012) experienced a decline in many countries. A few countries increased their spending on direct job-creation, even though evaluation studies agree that direct jobcreation does not have much impact on workers' qualification and is not good at bringing them back into ordinary employment (Christoph/Hohmeyer 2012; de Koning/Peers 2007). Spending on training, the prime measure from a social investment perspective, was not detected in our observation period, but instead declined further. In 2014/2015, not much more is spent on training per person wanting to work than on employment incentives or sheltered and supported employment and rehabilitation. 


\section{Summary and discussion}

Our descriptive analysis of European countries' spending on labour market policies between 2006 and 2015 shows that there is no real trend towards social investment in this field, despite the discursive dominance of the social investment paradigm in Europe since the early 2000s and its reaffirmation by EUCommission in 2013. This shows both in the relationship between passive and active spending and in the composition of active spending. Concerning levels of spending, labour market policy gets fiscally more demanding on aggregate, yet the amount of resources made available to the average individual job seeker shrinks in recent years. Spending also remains very unequal between European countries.

More in detail on the relationship between active and passive spending, we find that on average across European countries, passive spending dominates throughout our observation period, and that its advance over active spending is rather stable, apart from an even stronger emphasis on passive spending in the most turbulent crisis years. There is just a minority of countries that spend more on active LMP. In 2014/2015, it is Denmark, Sweden, Hungary, the Czech Republic, and Poland, while the majority of our 27 sample countries are inclined towards passive expenditure. We observe changing - and somewhat sharpening spending profiles in some countries in recent years, but no common trend toward either active or passive LMP.

The latter would not preclude an increasingly social-investment friendly character of spending if we consider the ambivalent nature of the broad categories of active and passive expenditure with regard to social investment. Yet, we also look at the components of ALMP spending that are strengthened, and weakened, during the observation period. Training is at the heart of social investment. On average across European countries, social investment was clearly the most prominent ALMP spending category at the beginning of our observation period in 2006. Yet, it gradually lost this distinguished status: by 2015, little additional funding is spent on training in comparison with the categories of employment incentives, sheltered and supported employment, and rehabilitation. This is striking provided the EU's emphasis on social investment and ist objective of fostering more knowledge-based economies.

In contrast, what is paradigmatic for the present phase of labour market policy is the aim of maximising the number of persons in employment, or who are at least economically active. Motivated by the objective to reduce the dependency ratio, this aim has also been discussed as a defining feature of social investment (De Deken 2013). It is thus not surprising that employment incen- 
tives become more important in many of our sample countries, relative to other measures. Often, employment incentives consist of temporary wage subsidies paid by the state either to workers (who can thus accept lower wages) or employers (who save money on salaries). We argue that this risks promoting the creation of particular low-productivity jobs connected to a knowledge-based economy only through their role in creating an environment of affordable services for highly-productive knowledge-intensive job holders. The combination of weakening training expenditure and strengthening employment incentives suggests that an increased polarisation of the labour market is politically acceptable as the cost of rising employment rates. The role that activation in the form of benefit conditions and sanctions may play here cannot be verified with spending data. The aspired additional jobs are predominantly dependent employment in the private sector: there is no extension of public job-creation except in some (not all) countries with particular labour market problems, and start-up incentives are at a broad downward trend.

Comparing levels of spending between European countries, we found that the classification of countries with active- versus passive-leaning labour market policies is not the most relevant distinction. Active and passive expenditure are highly correlated, with passive LMP receiving more resources in most countries. Rather, we can discern between countries spending little and countries spending more on LMP. This holds despite some convergence, following from a boost in ALMP in some Eastern European countries with very low initial spending and from strong reductions of PLMP spending in some countries with Continental welfare states and high initial spending.

Notwithstanding, we do observe some sort of "resource competition": not between types of LMP, but between job seekers. In most countries, the amount of resources granted to the average job seeker shrinks as the crisis unfolds after 2008. In the case of ALMP, this affects the value of training programmes, job subsidies, etc. We explain this with a rising demand for interventions in the face of partly (pre-)fixed budgets. Concerning PLMP, this does not necessarily have to do with welfare reform, even though social spending was curtailed in many European countries to make up for the fiscal losses connected to bank bailouts, stimulus packages and economic slowdown (ILO 2015: 128). Declining passive expenditure per person can also be a consequence of individual benefit entitlements running out in a phase of enduring labour market strain. We conclude that spending per person is not, as Hemerijck et al. (2013: 21) argue, "largely independent of the state of the economy". Presumably, however, reductions in spending per person would have been effectuated even without the crisis in some countries. According to a recent report to the European Commission (Bou- 
get et al. 2015: 37), cuts sometimes predate the 2008 crisis and do not concentrate on the most affected countries. In our sample, the country with the most important decline in absolute spending per person wanting to work is Luxembourg.

Additional Material: the online version of this article offers additional material (https://doi.org/10.1515/zsr-2018-0018).

\section{Bibliography}

Asztalos Morell, Ildikó (2014): “Workfare with a Human Face? Innovative Utilization of Public Work in Rural Municipalities in Hungary", Metszetek 3: 4-24.

Betcherman, Gordon; Olivas, Karina; Dar, Amit (2004): Impacts of Active Labor Market Programs: New Evidence from Evaluations with Particular Attention to Developing and Transition Countries. Social Protection Unit, Human Development Network, The World Bank, Social Protection and Labor Policy and Technical Notes 29142.

Bonoli, Giuliano (2012): “Active Labour Market Policy and Social Investment: A Changing Relationship”, in: Nathalie Morel; Bruno Palier; Joakim Palme (eds.): Towards a Social Investment Welfare State? Ideas, Policies and Challenges. Bristol: Policy Press, 181-204.

Bouget, Denis; Frazer, Hugh; Marlier, Eric; Sabato, Sebastiano; Vanhercke, Bart (2015): Social Investment in Europe: A Study of National Policies. Report of the European Social Policy Network (ESPN) to the European Commission.

Bruno, Randolph L.; Rovelli, Riccardo (2010): “Labour Market Policies and Outcomes in the Enlarged EU”, Journal of Common Market Studies 3: 661-685.

Cantillon, Bea (2011): “The Paradox of the Social Investment State: Growth, Employment and Poverty in the Lisbon Era", Journal of European Social Policy 5: 432-449.

Card, David; Kluve, Jochen; Weber, Andrea (2015): What Works? A Meta Analysis of Recent Active Labor Market Program Evaluations. IZA - Institute of Labor Economics, IZA Discussion Paper No. 9236.

Christoph, Bernhard; Hohmeyer, Katrin (2012): “Ein-Euro-Jobs aus Sicht der Betroffenen: Zur Binnenwahrnehmung eines kontroversen Instruments", Sozialer Fortschritt 6: 118-126.

Clasen, Jochen; Clegg, Daniel; Goerne, Alexander (2016): “Comparative Social Policy Analysis and Active Labour Market Policy: Putting Quality before Quantity”, Journal of Social Policy 1: 21-38.

Cronert, Axel (2017): “Unemployment Reduction or Labor Force Expansion? How Partisanship Matters for the Design of Active Labor Market Policy in Europe", Socio-Economic Review, https://doi.org/10.1093/ser/mwx014 (last accessed 28 August 2018).

De Deken, Johan (2012): Identifying the Skeleton of the Social Investment State: Defining and Measuring Patterns of Social Policy Change on the Basis of Expenditure Data. Conference paper at ESPANET 2012, Edinburgh, September 6-8, 2012.

de Koning, Jaap; Peers, Yuri (2007): Evaluating ALMP Evaluations. Erasmus School of Economics (SEOR), Working Paper 2007/2. 
Esping-Andersen, Gøsta (1990): The Three Worlds of Welfare Capitalism. Princeton: University Press.

ETUI, European Trade Union Institute (2018): Benchmarking Working Europe 2018. Brussels.

European Commission (2013): Towards Social Investment for Growth and Cohesion - Including Implementing the European Social Fund 2014-2020. European Commission, February 2013.

Eurostat (2008): European Price Statistics - An overview. Office for Official Publications of the European Communities, July 2018.

Eurostat (2013): Labour market policy statistics - Methodology 2013. Publications Office of the European Union, Manuals and Guidelines, 2013 Edition.

Hall, Peter A.; Soskice, David (2001): Varieties of Capitalism: The Institutional Foundations of Comparative Advantage. Oxford: University Press.

Hemerijck, Anton; Dräbing, Verena; Vis, Barbara; Nelson, Moira; Soentken, Menno (2013): European Welfare States in Motion. Neujobs, Neujobs Working Paper No. D5.2, March 2013.

ILO, International Labour Organization (2015): Building Economic Recovery, Inclusive Development and Social Justice. International Labour Organization, World Social Protection Report 2014/15, June 2014.

Kazepov, Yuri; Ranci, Costanzo (2017): “Is Every Country Fit for Social Investment? Italy as an Adverse Case", Journal of European Social Policy 1: 90-104.

Keller, Judit; Kovács, Katalin; Rácz, Katalin; Swain, Nigel; Váradi, Monika (2016): “Workfare Schemes as a Tool for Preventing the Further Impoverishment of the Rural Poor", Eastern European Countryside 1: 5-26.

Kuitto, Kati (2016): "From Social Security to Social Investment? Compensating and Social Investment Welfare Policies in a Life-Course Perspective”, Journal of European Social Policy 5: 442-459.

Lakner, Zoltán; Tausz, Katalin (2016): “From a Welfare to a Workfare State: Hungary”, in: Klaus Schubert; Paloma de Villota; Johanna Kuhlmann (eds.): Challenges to European Welfare Systems. Cham: Springer, 325-350.

Morel, Nathalie; Palier, Bruno; Palme, Joakim (2012): "Beyond the Welfare State as We Knew It?”, in: Nathalie Morel; Bruno Palier; Joakim Palme (eds.): Towards a Social Investment Welfare State? Ideas, Policies and Challenges. Bristol: Policy Press, 1-32.

Nelson, Moira (2013): “Making Markets with Active Labor Market Policies: The Influence of Political Parties, Welfare State Regimes, and Economic Change on Spending on Different Types of Policies”, European Political Science Review 2: 255-277.

Nicaise, Ides; Schepers Wouter (2013): "Social investment: the new paradigm of EU social policy?”, Belgisch Tijdschrift voor Sociale Zekerheid / Revue Belge de Sécurité Sociale 2, 189-230.

Nikolai, Rita (2012): “Social Investment: A Paradigm in Search of a New Economic Model and Political Mobilisation”, in: Nathalie Morel; Bruno Palier; Joakim Palme (eds.): Towards a Social Investment Welfare State? Ideas, Policies and Challenges, Bristol: Policy Press, 91117.

Streeck, Wolfgang; Mertens, Daniel (2011): Fiscal Austerity and Public Investment: Is the Possible the Enemy of the Necessary? Max-Planck-Institut für Gesellschaftsforschung, MPIfG Discussion Paper 11/12, June 2011.

Streeck, Wolfgang; Thelen, Kathleen (2005): Beyond Continuity: Institutional Change in Advanced Political Economies. New York: Oxford University Press. 
Szikra, Dorottya (2014): "Democracy and Welfare in Hard Times: The Social Policy of the Orbán Government in Hungary Between 2010 and 2014", Journal of European Social Policy 5 , 486-500.

van Vliet, Olaf; Koster, Ferry (2011): “Europeanization and the Political Economy of Active Labour Market Policies”, European Union Politics 2: 217-239.

Vandenbroucke, Frank; Vleminckx, Koen (2011): “Disappointing Poverty Trends: Is the Social Investment State to Blame?", Journal of European Social Policy 5: 450-471.

Vlandas, Tim (2013): “Mixing Apples with Oranges? Partisanship and Active Labour Market Policies in Europe”, Journal of European Social Policy 1: 3-20.

\section{Short Biography}

René Lehwess-Litzmann is a researcher at the Sociological Research Institute (SOFI) in Göttingen, Germany. He works on topics at the intersection of Sociology and Economics ("Socioeconomics"), focusing mainly on the labour market and the welfare state in European comparison and from a perspective of social change.

Abstract: Aus dem Blickwinkel der Sozialinvestition untersucht der Beitrag die monetären Anstrengungen, die europäische Länder zwischen 2006 und 2015 im Bereich aktiver und passiver Arbeitsmarktpolitik getätigt haben: Wie haben sich ihre Ausgaben unter dem Eindruck des Sozialinvestitionsdiskurses einerseits und der Krise ab 2008 andererseits entwickelt? Wie unterscheiden sie sich heute im Vergleich zu vor der Krise? Wir beobachten in den vergangenen Jahren keinen Trend zu mehr Sozialinvestition im Bereich der Arbeitsmarktpolitik, weder im Verhältnis zwischen passiven und aktiven Ausgaben noch in der Zusammensetzung der Letzteren. Insbesondere Qualifizierungsausgaben, zentral für Sozialinvestition, wurden in den meisten Ländern eher geschwächt als gestärkt. Mit Blick auf Ausgabenniveaus zeigt sich, dass Arbeitsmarktpolitik zwar insgesamt fiskalisch kostspieliger wurde, die dem/der einzelnen Arbeitssuchenden zur Verfügung gestellten Ressourcen aber abnahmen. Zwischen europäischen Ländern bestehen nach wie vor deutliche Unterschiede, was die Größenordnung arbeitsmarktpolitischer Ausgaben betrifft. 